\title{
A Modernidade na arquitetura hospitalar: contribuições para a historiografia
}

\author{
Autor reseña: RENATO ANELLI · USP - São Carlos
}

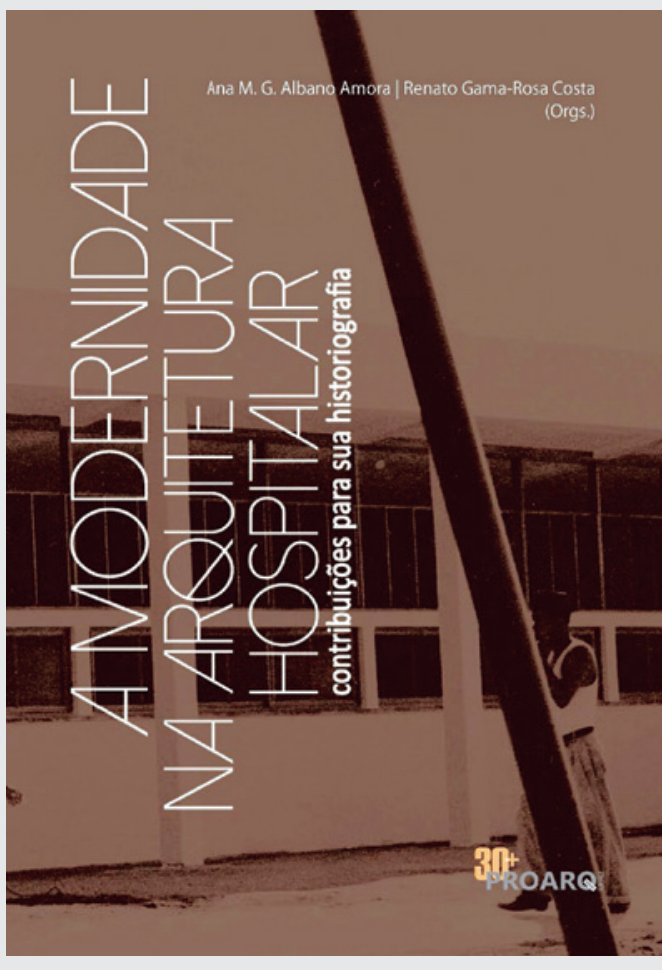

"A MODERNIDADE NA ARQUITETURA HOSPITALAR: CONTRIBUIÇÕES PARA A HISTORIOGRAFIA"

Ana M. G. Albano Amora e Renato Gama-Rosa Costa (Organizadores).

Rio de Janeiro: Programa de Pós-Graduação em Arquitetura - Faculdade de Arquitetura e Urbanismo. 2019

ISBN 978-65-81518-00-4 • ISBN 978-65-00-00894-4 Disponible en línea:

http://www. proarq.fau.ufri.br/public/editor/LIVROS\%20 ED\%20PROARQ/Arquitetura\%20Hospitalar-FINAL.pdf

\footnotetext{
E I libro "A Modernidade na arquitetura — hospitalar: contribuições para a historiografia" ofrece al lector una introducción coherente a la historia de la arquitectura de las instalaciones sanitarias, permitiendo la comprensión de sus transformaciones junto con las de la medicina. En esta trayectoria, se pueden destacar dos momentos. El primero de
}

ellos está asociado al desarrollo de la tipología de pabellones horizontales separados entre sí, alejados de la ciudad para cumplir con las estrategias médicas para aislar a los enfermos. La aparición de nuevos medicamentos permitió la inserción de los hospitales en zonas urbanas. Los arquitectos desarrollaron proyectos alineados con los principios de las vanguardias modernas. De esta manera, el segundo momento es el de los edificios desarrollados verticalmente para lograr una mejor localización, el control de los flujos para evitar la contaminación, los nuevos dispositivos de confort ambiental para controlar el calor y la renovación del aire, los entornos adecuados para el equipamiento y la acogida psicológica de los pacientes. Así, los hospitales modernos se convirtieron en un ejemplo del rol de los arquitectos como coordinadores de varias disciplinas del conocimiento, tal como señala Amora citando a Rino Levi en el primer capítulo de la publicación.

El libro es resultado de un seminario internacional realizado en Río de Janeiro el año 2014 y está compuesto por capítulos desarrollados por autores de Brasil, Canadá, Chile, Colombia y México. Estos capítulos ofrecen un panorama del proceso de modernización social a través del desarrollo de la medicina y la arquitectura -sus desafíos, teorías, procedimientos e instalaciones-, dando cuenta a su vez de la superación de la condición colonial y la formación de naciones independientes en América del Sur, Central y del Norte. Por esta razón, la modernización se entiende como un período más amplio que la producción arquitectónica y artística impulsada en el marco de las vanguardias. Al respecto, la posición geográfica es interesante, porque las condiciones climáticas y políticas perfilaron los retos a los que se enfrentaba la medicina y la arquitectura. Estas condiciones particulares, exigieron la necesaria adaptación de las teorías europeas y la creación de centros de investigación. Por tanto, las especificidades surgen dentro de los contexto nacionales y regionales: variaciones en la periodización, en las políticas públicas, instituciones y prioridades.

El caso de Brasil es, obviamente, el más predominante del libro. Hay estudios sobre el impacto de las teorías de la microbiología en los proyectos hospitalarios de Río de Janeiro a finales del siglo XIX; el papel de Oswaldo Cruz y su arquitecto Luís de Moraes Junior; la transición desde las instituciones filantrópicas de la Primera República a las redes hospitalarias que se extienden por todo el territorio nacional a partir del primer gobierno de Getúlio Vargas, descentralizando la arquitectura hospitalaria de calidad, revelando obras que van mucho más allá de la contribución de Luis Nunes en Pernambuco.

Por otra parte, la ocupación del territorio guía dos casos de estudio a partir de situaciones histórico-geográficas específicas que dan cuenta de lo ocurrido en Chile (Antofagasta durante la Guerra del Pacífico) y en Colombia en el lazareto de Agua de Dios. La periodización de la modernización varía de un país a otro. Los hospitales urbanos verticales de Canadá preceden a la arquitectura vanguardista, siguiendo estilos historicistas de la Costa Este de Estados Unidos. A su vez, la revolución Mexicana inaugura las políticas públicas a gran escala en 1920, años antes de que ocurra en Brasil con Getulio Vargas.

Junto con dominar los conocimientos propios de la historia de la arquitectura, varios de los autores que participan de este libro recurren a las principales teorías críticas de la medicina como medio de control social. Publicado en un contexto marcado por una nueva pandemia en la que, a falta de medicamentos, el aislamiento vuelve a ser la estrategia central, este libro permite reflexionar sobre la temporalidad de las certezas científicas y el rol en este campo asumido por la arquitectura. 